\title{
Uso indebido de la figura de la sociedad cooperativa
}

\author{
Luis Ángel Díez Ácimas \\ Funcionario de la Administración General del Estado \\ Ex coordinador de servicios de la Dirección de Economía Local de Castilla y León
}

Sumario: I. Introducción. II. Uso fraudulento, uso abusivo o uso indebido. 1. Fraude. 2. Abuso de derecho. 3. Distinción entre fraude de ley y abuso de derecho. 4. Simulación. III. Supuestos de uso indebido de la figura de la sociedad cooperativa: cooperativas de viviendas. iv. supuestos de uso indebido de la figura de la sociedad cooperativa: cooperativas de trabajo: 1. Empresario que constituye cooperativas para no tener trabajadores integrados en su plantilla. 2. Trabajador autónomo enmascarado en sociedad cooperativa. 3. Conjunto de trabajadores autónomos que no realizan actividad cooperativizada. 4. Subcontratación. 5. Creación de cooperativas instrumentales para facturar trabajos de autónomos. V. Las nuevas fórmulas cooperativas previstas en la normativa aprobada recientemente: cooperativas de impulso empresarial. 1. Ley 14/2011, de 23 de diciembre, de Sociedades Cooperativas Andaluzas. 2. Decreto 123/2014, de 2 de septiembre, por el que se aprueba el Reglamento de la Ley 14/2011, de 23 de diciembre, de Sociedades Cooperativas Andaluzas. 3. Ley de Cantabria 6/2013, de 6 de noviembre, de Cooperativas de Cantabria. 4. Reflexiones sobre estas cooperativas. VI. Medidas de vigilancia y actividades de inspección.

Resumen: El elevado número de sociedades cooperativas constituidas en los últimos años nos obliga a ser optimistas sobre la contribución de éstas al desarrollo social y al crecimiento económico y a pensar que en el futuro próximo seguiremos asistiendo al nacimiento de muchas empresas de esta naturaleza. Pero, la observación de la realidad empresarial, también, nos obliga a denunciar la existencia de sociedades cooperativas que optan por este revestimiento jurídico para obtener el régimen propio de éstas cuando su verdadera naturaleza dista mucho de los principios y características propias de las cooperativas.

Por otro lado, se quiere destacar la necesidad de que la normativa sobre esta materia sea respetuosa con la esencia del modelo cooperativo y que las diferentes administraciones públicas con competencias sobre estas empresas realicen una adecuada labor de vigilancia para garantizar el respeto de estas a la legislación y a los principios cooperativos.

Palabras clave: Cooperativa. Fraude. Legislación adecuada. Inspección. 
Abstract: The large number of cooperative societies created in recent years makes us optimistic about their contribution to social development and economic growth. This also leads us to think that there will be an increase in companies of this type in the near future. However, we must draw attention to the fact that many companies are opting for this legal form although their true nature is far from the principles and characteristics of cooperatives.

On the other hand, we intend to highlight the need for legislation in this field to respect the essence of the cooperative model and adequate oversight from the various regulatory agencies to ensure compliance with this legislation and cooperative principles.

Key words: Cooperative. Fraud. Appropriate legislation. Oversight. 


\section{Introducción}

La contribución de las empresas de economía social; y, concretamente, de las cooperativas a la creación de empleo, al desarrollo local, a la generación de cohesión social y a la participación democrática está perfectamente acreditada. Este papel que desempeñan en todo momento debe ser valorado aún más en las épocas de crisis económica en que su presencia en la vida socioeconómica adquiere especial relevancia y donde el enorme esfuerzo de muchas personas para crear o mantener su propio empleo resulta encomiable.

Sin pretender cuestionar estas importantes aportaciones del cooperativismo a la sociedad, vamos a comentar aquellos casos en que, bajo la forma de sociedad cooperativa, se ocultan realidades que distan mucho de ser sociedades que participen de los principios propios de este movimiento. Queremos reflejar esas empresas que formalmente son cooperativas, pero que su verdadera naturaleza es otra muy distinta, y adoptan esta forma para obtener, por ejemplo, un régimen fiscal o de seguridad social que no les correspondería o acceder a ayudas públicas a las que con otra forma social no tendrían derecho o para privar de derechos laborales a los trabajadores.

Supuestos de este tipo se dan en las diferentes clases de cooperativas; pero, dado el gran volumen de las cooperativas de vivienda y de trabajo, y la frecuencia con que, en la experiencia, nos hemos encontrado con casos de este tipo en las mencionadas clases de cooperativas, será a éstas a las que nos referiremos especialmente.

No se pretende demonizar a las sociedades cooperativas por las malas prácticas de algunas de ellas; al contrario, queremos resaltar la importancia social y económica de las que participan de los principios y del auténtico movimiento cooperativo y hacer una llamada de atención a los poderes públicos para que se ejerza una labor de control serio y riguroso sobre aquellas que dañan gravemente la imagen del cooperativismo y pedir la complicidad de las entidades asociativas del sector para que traten de aislar estas prácticas tan poco edificantes para el mundo cooperativo.

La existencia de estas situaciones no se produce exclusivamente en nuestro país, también, se da insistentemente a nivel internacional, como se manifiesta en el discurso, pronunciado el pasado 28 de febrero de 2015, por el Papa Francisco ante los representantes de la Confederación Italiana de Cooperativas en la que denuncia con contunden- 
cia la creación de falsas cooperativas e incita al movimiento asociativo de éstas a trabajar por su erradicación'1.

También reflexionaremos sobre las formas legales de cooperativismo que se regulan en las legislaciones más recientes; y, que, entendemos, que con su reconocimiento legal se corre el riesgo de otorgar la carta de naturaleza cooperativa a entidades que distan mucho de ser verdaderas sociedades que participen de su verdadera esencia.

\section{Uso fraudulento, uso abusivo o uso indebido}

Afrontar el tema de la utilización indebida de la figura de la sociedad cooperativa, para dar cobertura a realidades que distan mucho de ser verdaderas sociedades de este tipo, es una tarea difícil y delicada. Tan complicado resulta el enfoque del asunto, que incluso decidir un título para este análisis resulta complejo. Por lo tanto, el primer reto que nos encontramos es explicar porque hablamos de uso indebido que es un término menos duro que uso fraudulento o uso abusivo. La razón principal obedece al deseo de reflejar situaciones que constituyen fraude de ley, otras que constituirían abuso de derecho y otras que, incluso desde dentro de la legalidad, entendemos que no son un ejemplo correcto de lo que entendemos que debe de ser una sociedad cooperativa. Para evitar calificar con excesivo rigor (y caer en errores de calificación) algunas de estas conductas, nos limitamos a

1 En este discurso, cuyo texto íntegro está disponible, entre otros, en el sitio web «http://www.economiasolidaria.org/documentos/» podemos leer lo siguiente: «Por esto os digo que hacéis bien - y os digo también de hacerlo cada vez más- en oponeros y combatir las falsas cooperativas, las que prostituyen el propio nombre de cooperativa, es decir, de una realidad tan buena, para engañar a la gente con fines de lucro contrarios a los de la verdadera y auténtica cooperación. Hacéis bien, os lo digo, porque, en el campo en el que actuáis, asumir una fachada honorable y perseguir en cambio fines despreciables e inmorales, a menudo dirigidos a la explotación del trabajo, o incluso a las manipulaciones de mercado, y hasta escandalosos tráficos de corrupción, es una vergonzosa y gravísima mentira que no se puede aceptar de ninguna manera. ¡Luchad contra esto! ¿Pero cómo luchar? ¿Sólo con las palabras? ¿Con las ideas? Luchad con la cooperación justa, la verdadera, la que siempre vence. La economía cooperativa, si es auténtica, si quiere desempeñar una función social fuerte, si quiere ser protagonista del futuro de una nación y cada una de las comunidades locales, debe perseguir finalidades transparentes y claras. Debe promover la economía de la honradez. Una economía saneada en el mar insidioso de la economía global. Una verdadera economía promovida por personas que tienen en el corazón y en la mente sólo el bien común». 
referir los supuestos de uso indebido de la figura de la sociedad cooperativa, sin añadir etiquetas.

Aunque hayamos optado por esa suave terminología, en primer lugar, vamos a hacer algunas reflexiones generales sobre los conceptos de fraude de ley, abuso de derecho y simulación; supuestos, todos ellos, que nos vamos a encontrar en el mundo que se mueve bajo un concepto amplio de lo cooperativo; para analizar, después, esos supuestos de sociedades cooperativas que son utilizadas como máscaras para ocultar diversas intenciones que hemos podido conocer de la observación de la realidad empresarial.

\section{Fraude}

Este concepto es definido, en la segunda acepción del Diccionario de la Real Academia Española (DRAE) como «acto tendente a eludir una disposición legal en perjuicio del Estado o de terceros». Este concepto, sólo se centra en los perjudicados y no reflejaría la intención de obtener un beneficio por parte del autor del acto.

Se puede conceptualizar el fraude, a los efectos que a nosotros nos interesan, como el acto tendente a eludir el cumplimiento de una norma legal en perjuicio del Estado (en sentido amplio) o de terceros y en beneficio propio de quien lo realiza.

El fraude supone la realización de un acto o negocio jurídico amparándose en una norma (ley de cobertura) con la finalidad de alcanzar ciertos objetivos, que no siendo propios de esa norma, sean además contrarios a otra ley (ley defraudada) o al ordenamiento jurídico. Estaríamos, por tanto, ante la vulneración de la norma jurídica al amparo, aparente, de otra norma o disposición diversa, es decir, al haber un acto que se relaciona con dos normas distintas, viola una con aparente apoyo en la otra.

En la legislación española, se define el fraude de ley en el artículo 6.4 del Código Civil en los siguientes términos: «Los actos realizados al amparo del texto de una norma que persigan un resultado prohibido por el ordenamiento jurídico o contrario a él, se considerarán ejecutados en fraude de ley y no impedirán la debida aplicación de la norma que se hubiere tratado de eludir».

Por lo tanto, los efectos previstos por la normativa para el acto realizado en fraude de ley es la aplicación de la norma que se trata de eludir. Pero el problema fundamental es la constatación de que se produce una situación de este tipo, hay que lograr desvirtuar la apariencia de legalidad de la que se cubre el acto fraudulento, lo que, generalmente, no es nada fácil. 
De la realidad constatada al respecto, se deriva una gran dificultad de ofrecer un concepto claro e inequívoco del fraude en materia de constitución y utilización de sociedades cooperativas con diferentes finalidades, ya que los supuestos que podemos encontrarnos son muy diversos, por lo que optaremos por un examen casuístico más que por crear categorías genéricas.

Además, del problema de conceptuación nos encontramos con otro aún más importante y es que ante la comprobación de una situación anómala hay que constatar y demostrar que se ha producido dicha irregularidad con el objetivo de obtener beneficios indebidos ${ }^{2}$. $Y$ comprobada la existencia de la conducta hay que valorar si hay norma punitiva que permita sancionar por esa actuación. Cuando se da este caso, no siempre es fácil encontrar la norma que tipifique y sancione la conducta por lo que hay que acudir a la normativa general antes referida, en concreto al artículo 6.4 del Código Civil.

Como señala reiteradamente la jurisprudencia ${ }^{3}$, el fraude no se presume, ha de acreditarse por quien lo invoca. Sólo podrá declararse si existen indicios suficientes de ello, que necesariamente habrán de extraerse de hechos que hayan sido probados. No podemos olvidar el derecho a la presunción de inocencia que consagra el artículo 24.2 de la Constitución Española, lo que obliga a utilizar con gran cautela las pruebas indiciarias.

Según el Tribunal Constitucional (STC 120/2005, de 10 de mayo) el concepto de fraude de ley (tributaria o de otra naturaleza) nada tiene que ver con los conceptos de fraude o de defraudación propios del derecho penal ni, en consecuencia, con los de simulación o engaño que les son característicos. La utilización del término "fraude» como acompañante a la expresión «de ley» acaso pueda inducir al error de confundirlos, pero en puridad de términos se trata de nociones esencialmente diversas. En el fraude de ley (tributaria o no) no hay ocultación fáctica sino aprovechamiento de la existencia de un medio jurídico más favorable (norma de cobertura) previsto para el logro de un fin diverso, al efecto de evitar la aplicación de otro menos favorable (norma principal).

2 FERNÁNDEZ ORRICO, F. J. «La Inspección de Trabajo frente al fraude en las prestaciones de Seguridad Social». Ministerio de Empleo y Seguridad Social. 2014. Aunque centrado en el fraude en las prestaciones de Seguridad Social, en el capítulo I «Delimitación del fraude en las prestaciones y actuación de la Inspección de Trabajo» se realizan reflexiones muy interesantes sobre el fraude que pueden ayudar a conceptuar éste en otras materias, como la que nos ocupa.

3 Se reitera esta exigencia constantemente en la Jurisdicción Social, por todas ellas STS de 14 de mayo de 2008 y STS de 12 de mayo de 2009. 
Por lo que se refiere en concreto al fraude de ley tributaria, sigue diciendo esta sentencia, semejante «rodeo» o «contorneo» legal se traduce en la realización de un comportamiento que persigue alcanzar el objetivo de disminuir la carga fiscal del contribuyente aprovechando las vías ofrecidas por las propias normas tributarias, si bien utilizadas de una forma que no se corresponde con su espíritu.

De igual forma podemos razonar cuando se pretende defraudar en materia de seguridad social, pero, no olvidemos que en nuestro caso hay ocasiones que los perjudicados no son las Administraciones Públicas, sino personas que se ven privadas (o mermadas) de sus derechos como consumidores o como trabajadores

En conclusión, de todo lo dicho, se puede afirmar la existencia de fraude de ley cuando se acreditan los siguientes hechos y conductas:

- Negocios jurídicos realizados con la finalidad exclusiva de conseguir una ventaja. Esta se constituye en su causa esencial.

- Utilización de una serie de normas que dan cobertura a las citadas operaciones y la existencia de normas que son eludidas, dentro de una actuación en fraude de ley.

\section{Abuso de derecho}

Esta figura es definida por el DRAE como «ejercicio de un derecho en sentido contrario a su finalidad propia y con perjuicio ajeno». En el abuso de derecho estaríamos, por tanto, ante la acción cometida por el titular de un derecho, pero al margen de su finalidad. Se trataría, por tanto, del ejercicio de un derecho excediendo los límites fijados por la buena fe o por el fin para el cuál ese derecho se ha conferido. Debemos entender que los derechos subjetivos no son ilimitados. El derecho no puede amparar ese proceder inmoral del titular de un derecho.

En estos casos el término derecho no debe tomarse en el sentido de ordenamiento jurídico, sino referido exclusivamente a los derechos subjetivos; $y$, en concreto, a las facultades que integran su contenido.

\section{Distinción entre fraude de ley y abuso de derecho}

De forma sintética se pueden establecer sus diferencias de la siguiente manera4:

${ }^{4}$ FERNÁNDEZ ORRICO, F. J op. cit. p. 58. 
- El fraude de ley consiste en un comportamiento en sí mismo considerado como ilícito dirigido para obtener un fin lícito, mientras que el abuso de derecho se caracteriza por ocasionar perjuicios a terceros mediante el ejercicio desmesurado de una facultad.

- En el fraude de ley, lo inadecuado es la finalidad perseguida, en el abuso de derecho lo incorrecto es el comportamiento del sujeto.

\section{Simulación}

La simulación es el encubrimiento convenido de una realidad jurídica mediante una falsa apariencia jurídica, que acarrea la inexistencia de lo aparentado, siendo la reacción frente a la misma el desvelamiento de la verdadera realidad jurídica.

Las partes conciertan un acuerdo de forma consciente cuyo contenido o finalidad es distinta de la que manifiestan al exterior.

En este caso, se oculta un acto bajo la apariencia de otro, en el fraude se coloca un acto bajo la protección de una norma que no es la que lo tutela adecuadamente.

Ahora bien, el problema surge especialmente en la simulación de la causa por su estrecha vinculación con la finalidad o propósito que las partes persiguen al celebrar un contrato. Así se considera que un contrato realizado no con el fin habitual o normal, sino para el logro de un resultado singular adolece de vicio en la causa, y al apartarse de la «causa típica» o carecer de ella merece la calificación de simulado.

\section{Supuestos de uso indebido de la figura de la sociedad cooperativa: cooperativas de viviendas}

La existencia de empresas que utilizan la forma societaria de cooperativa cuando ocultan una realidad que difiere sustancialmente de la esencia de éstas, se produce utilizando formalmente cualquier clase de cooperativa de las previstas en la normativa; pero, los casos más habituales se producen, como señalábamos al principio, en cooperativas de viviendas y de trabajo, por lo que nos centraremos en el análisis de estos supuestos.

Respecto a las cooperativas de vivienda es frecuente encontrar supuestos en que, como explica Zubiri de Salinas ${ }^{5}$, son las empresas ges-

5 ZUBIRI DE SALINAS, M. «Las empresas gestoras de cooperativas de viviendas tras la reforma de la Ley de Cooperativas de Aragón. Revista: Actas del Foro de Derecho Aragonés Volumen: XX; pp. 261-276. 
toras de las cooperativas las gestantes de las propias cooperativas. Son ellas, como empresas dedicadas a la gestión inmobiliaria, las que captan los socios y promueven la constitución de las cooperativas a las que se van adhiriendo las personas interesadas en la adquisición de una vivienda en las mejores condiciones de precio y calidad. Suele coincidir la empresa gestora con la promotora de la cooperativa. Esto puede plantear un primer problema, sigue manifestando esta autora, y es que la empresa gestora se oculte tras el velo de la cooperativa reservándose los beneficios en forma de retribución por la gestión (o los costes repercutidos a través de diversas contratas), mientras que traslada los riesgos a los futuros titulares de las viviendas, de los que obtiene la financiación que el sector crediticio le niega. Continúa señalando que en épocas de especial dificultad para conseguir el acceso a la financiación, se idean técnicas, en ocasiones, poco ortodoxas para conseguirla. El empresario promotor impulsa sus nuevas promociones bajo forma de cooperativa, actuando como un promotor de hecho, aunque de derecho sea un tercero ajeno a la cooperativa.

Con esta forma de proceder, se rompe el principio básico de que la cooperativa debe surgir de abajo a arriba y no a la inversa como ocurre en estos casos. El camino correcto sería que los socios que inician el proyecto buscasen el apoyo profesional de una gestora. Con este procedimiento de "adhesión» a la gestora se llega, en ocasiones, a situaciones en las que los socios desconocen sus derechos y obligaciones como cooperativistas, porque no tienen, en absoluto, conciencia de tal condición y no participan en la elaboración de los estatutos y toma de decisiones importantes para el desarrollo y buen fin de la cooperativa.

\section{Supuestos de uso indebido de la figura de la sociedad cooperativa: cooperativas de trabajo}

Respecto a las cooperativas de trabajo, la casuística es muy variada y vamos a repasar, a continuación, diferentes supuestos con los que nos podemos encontrar.

1. Empresario que constituye cooperativas para no reconocer la relación de carácter laboral con los trabajadores e integrarlos en su plantilla

Esta práctica se produjo con mucha frecuencia en los años 80 del siglo anterior, en no pocas regiones españolas, en el sector textil, aunque no en exclusiva en el mismo. Con ella, un empresario crea una o 
varias sociedades cooperativas que producen los artículos que él mismo encarga, convirtiéndose en el único cliente de la cooperativa. Facilita la maquinaria, locales e inversiones más importantes, para que la aportación de los socios no sea muy alta y resulte apetecible para éstos participar en la misma. Controla la producción de la cooperativa e incluso los órganos de ésta.

En ocasiones, exige unos niveles de producción tan altos que hace imposible que los socios puedan llegar a repartirse en concepto de anticipo societario una cantidad similar a las retribuciones en el sector y la zona y se puedan satisfacer las cotizaciones a la Seguridad Social, lo que genera situaciones en las que se trabajan más horas y en peores condiciones de las que permitiría la aplicación de la normativa laboral. Ante esta situación, muchas cooperativas tienen una corta vida y el empresario, una vez finiquitada ésta, crea una nueva sociedad para seguir operando de la misma manera.

Aquellas que tienen más suerte y pueden alcanzar los niveles de producción suficientes para obtener unos ingresos normales en el sector se ven en una situación de dependencia absoluta del promotor y único cliente que tiene la llave de la permanencia de la cooperativa, haciendo encargos de trabajos a ésta o dejándolos de hacer cuando la actividad se hace más rentable contratando su ejecución en terceros países y abocando a la cooperativa al cierre.

En este caso, estamos ante empresarios que no quieren integrar en sus plantillas a los trabajadores y respetar todas las garantías que a éstos ofrece la normativa laboral y les obliga a constituir una sociedad cooperativa, si quieren tener un puesto de trabajo; pero éstos no tienen ninguna autonomía para gestionar la empresa porque es dirigida de forma oculta ( $y$, a veces, nada oculta, con presencia de sus representantes en el control del proceso productivo y en la toma de decisiones) por ese empresario. Es decir se simula una cooperativa, en la que los socios no establecen sus estatutos, ni ejercitan soberanamente los derechos que corresponden a sus órganos sociales.

Con esto, consigue reducir los costes salariales durante todo el periodo de actividad y no abonar las indemnizaciones que en concepto de despido corresponderían a los trabajadores si se les reconociese tal condición, llegado el caso.

Hemos querido contemplar separadamente este supuesto del fenómeno de la subcontratación poco ortodoxa, que analizaremos más adelante, para recalcar el carácter tan burdo de los casos aquí reflejados, en los que existe un empresario que no asume tal papel y en los que no se trata ni de simular una subcontratación, para tratar de ofrecer una apariencia de legalidad. 


\section{Trabajador autónomo enmascarado como sociedad cooperativa}

En este caso estamos ante un trabajador autónomo que para acceder a las ventajas que ofrece la legislación sobre sociedades cooperativas, tales como la elección de régimen de Seguridad Social para los socios de las cooperativas de trabajo, el acceso a ayudas públicas que se otorgan en exclusiva a empresas de economía social, la capitalización de la prestación por desempleo, constituye una cooperativa con, normalmente, miembros de su familia, hasta alcanzar el número mínimo de socios que exija la normativa aplicable y que no ejercen ninguna actividad profesional en la sociedad. Estos otros socios, de forma inmediata, pasan a situación de excedencia cooperativa. Cuando la administración competente les advierte de que no disponer del número mínimo de socios activos puede ser causa de descalificación de la cooperativa, se opta porque esos socios pasen a tener una jornada a tiempo parcial mínima (por ejemplo, una hora a la semana).

El trabajador autónomo emboscado en la cooperativa ha podido percibir el pago único de la prestación por desempleo, elegir el Régimen General de la Seguridad Social, percibir subvención por incorporarse como socio a la cooperativa o por realizar inversiones; pero, no estamos ante una cooperativa porque falta el ejercicio de actividad cooperativizada, ya que sólo trabaja una persona. Se constituye una cooperativa simulada para obtener los beneficios que la legislación otorga a éstas; pero, evidentemente, en realidad no lo es.

Para evitar estas situaciones, algunas leyes de cooperativas obligan a que el mínimo número de socios exigidos por la normativa para constituir una cooperativa presten servicios en ésta, con un mínimo grado de vinculación, por ejemplo, durante media jornada. Esta previsión se hace, al menos, en la Ley 4/2002, de 11 de abril, de Cooperativas de Castilla y León ${ }^{6}$ y en la Ley 6/2013, 6 de noviembre, de Cooperativas de Cantabria?.

${ }^{6}$ La Ley 9/2004, de 28 de diciembre, de Medidas Económicas, Fiscales y Administrativas, añade un párrafo al artículo 103 para tratar de atajar tal situación. El texto es el siguiente «El número mínimo de socios fijado en el artículo 5 de esta Ley deberá realizar una prestación de servicios de, al menos, el $50 \%$ de la jornada habitual en el sector de actividad en que esté encuadrada la cooperativa. En el caso de que no haya convenio colectivo aplicable se tomará como referencia la jornada máxima prevista en el Estatuto de los Trabajadores. El incumplimiento de este requisito relativo a la jornada de prestación de servicios del número mínimo de socios será causa de disolución de las cooperativas de trabajo».

7 El artículo 103.1 (segundo párrafo) establece la misma regulación que la Ley de Castilla y León. 


\section{Conjunto de trabajadores autónomos que no realizan actividad cooperativizada}

En este supuesto nos encontramos con una cooperativa que está formalmente constituida, cumpliendo todas las exigencias para que ésta inicie su actividad. Posteriormente, se aprecia que la cooperativa no inscribe, normalmente, ningún acto en el Registro de Cooperativas, ni efectúa en el mismo depósito alguno. Esto viene acompañado de la constatación de la situación real, que es que cada socio adquiere sus materias primas o los productos acabados para su comercialización, realiza sus trabajos de forma totalmente independiente y factura directamente los mismos y percibe los correspondientes pagos del cliente.

De lo expuesto, se deduce claramente que no existe la actividad cooperativizada en ninguna fase del proceso productivo, ya que no hay adquisición conjunta de materiales, no hay comercialización de bienes o servicios en común, no hay trabajo realizado en régimen cooperativo, no hay medios de producción de los que sea titular la sociedad cooperativa, ni hay facturación por parte de ésta. No habría elementos, pues, para entender que estemos ni ante una cooperativa de servicios, ni de trabajo.

Este caso se da habitualmente en cooperativas dedicadas a la venta ambulante en los populares mercadillos, en que la única gestión que se realiza en común es la tramitación de las licencias de venta ambulante ante los ayuntamientos correspondientes, que «imponen» en cierta medida la opción cooperativa para agilizar la gestión de las autorizaciones de venta ambulante con un único interlocutor y no con todos los comerciantes.

En aquellos casos en que las administraciones competentes en materia de cooperativas han procedido a resolver su descalificación por carecer de actividad cooperativizada e inactividad de los órganos sociales de forma continuada, se procede de forma inmediata a constituir con los mismos miembros una nueva cooperativa de idénticas características.

La situación originada por la existencia de estas cooperativas ha llevado incluso a la modificación de la normativa general sobre la elección del régimen de Seguridad Social para las cooperativas de trabajo, imponiendo en los casos en que los socios trabajadores de estas cooperativas perciban ingresos directamente de los compradores, la inclusión obligatoria en el Régimen Especial de la Seguridad Social para los Trabajadores Autónomos, con unas condiciones especiales de cotización ${ }^{8}$.

8 Para el ejercicio 2015, estas condiciones se fijan en el artículo 103, cinco, 8 de la Ley 36/2014, de 26 de diciembre, de Presupuestos Generales del Estado para el año 2015. 
Situación similar se da, en algunos casos, con las cooperativas dedicadas a la actividad de marisqueo, cuando las administraciones competentes para adjudicar las parcelas para la realización de esta actividad no las conceden a mariscadores individualmente considerados, sino a colectividades de los mismos, que forman cooperativas, pero actuando de la misma forma que explicábamos anteriormente, lo que origina que los socios no tengan ninguna sensación de participar en una empresa de titularidad colectiva.

En estos casos, podemos apreciar la existencia de unas prácticas administrativas inadecuadas, que anteponen la simplificación de sus actuaciones y procedimientos al respeto a la verdadera esencia cooperativa.

\section{Subcontratación}

En el estado actual del mundo de la producción, explica Martínez Garrido $^{9}$ la externalización de gran parte de la actividad ha dejado de ser una decisión voluntarista por parte del empresario. A esta situación, hay que añadir la falta de precisión en la limitación de la forma más frecuente de llevarla a cabo, la subcontratación y la pseudocontrata o la cesión ilegal de trabajadores. En el complejo mundo del mercado, sigue afirmando este autor, irrumpen con gran fuerza las empresas de servicios y las cooperativas de trabajo. Respecto a estas últimas, que son las que nos interesan, debemos de tener en cuenta que por mandato legal, la relación entre la cooperativa y el socio trabajador es societaria, no siendo aplicable la legislación laboral, salvo que expresamente se disponga lo contrario en la normativa, como ocurre expresamente con la de prevención de riesgos laborales.

Es importante deslindar la subcontratación de la figura prohibida de la cesión ilegal de trabajadores. Lo que prohíbe nuestro ordenamiento es la contratación en la que el objeto no es una obra o servicio, sino la pura cesión de mano de obra. Lo ilegal no es contratar mano de obra, sino que una vez realizada esta, no se incorpora a los trabajadores contratados a la empresa a la que, verdaderamente, va a prestar servicios. Es esa falta de incorporación la que determina que estemos ante la interposición en la figura del empresario que aparenta ser quien en verdad no lo es.

9 MARTínEZ GARRIDO, L. R., "Contratas, cesión ilegal de trabajadores y cooperativas de trabajo asociado». Revistas del Ministerio de Trabajo y Asuntos Sociales, n.$^{\circ} 38$. 2002. Pp. 229-239. 
Esta táctica supone la existencia de una empresa comitente que no dispone de personal propio suficiente para realizar determinadas actividades en un plazo concreto. En lugar de proceder a la contratación del personal necesario para contar con una plantilla suficiente para atender a esas circunstancias de la producción, opta por ejecutar los trabajos utilizando a todo el personal de una sociedad cooperativa que no es propietaria de los medios de producción, ni asume el riesgo empresarial, ni tiene control sobre la actividad. La prestación de servicios tiene apariencia de legalidad; pero, el indicio del fraude de ley será, según Martínez Garrido, la constatación de que los socios trabajadores disfruten de peores condiciones de las que corresponden a la empresa servida. En este caso, los efectos serán los previstos en el artículo 6.4 del Código Civil, debiéndose aplicar la norma tratada de eludir que es el convenio colectivo de la empresa comitente y las condiciones laborales recogidas en el mismo y en el resto de la legislación laboral aplicable.

En este caso, una cooperativa, cuyos socios desconocen los derechos y obligaciones inherentes a tal condición, se convierte en una sociedad instrumental de la que se hace un uso fraudulento, como denunció Vicent Comes $^{10}$ en un periódico regional con motivo de un accidente mortal. Afirma que si esos trabajadores no son conscientes de que son dueños de su trabajo y no participan de manera democrática en la toma de decisiones que afectan a la estrategia de la entidad, realmente, no hay cooperativa.

Estas actuaciones, que suponen la negación de la esencia del cooperativismo que nace para resolver las necesidades de sus integrantes por medio de su esfuerzo y la ayuda mutua, lo cuál no da cabida a la intermediación e interposición lucrativas que se pretenden con estas prácticas, no se ha producido exclusivamente en España. Así, por ejemplo, en Argentina se ha llegado a legislar de forma muy estricta la subcontratación y la intermediación con empresas cooperativas para evitar el fraude laboral, al entender que existe un conflicto entre las cooperativas y el derecho del trabajo.

La práctica de este tipo de actuaciones ha sido tan relevante en este país que una publicación de la Pontificia Universidad Católica Ar-

10 Vicent Comes, Presidente de la Federación Valenciana de Empresas Cooperativas de Trabajo Asociado (FEVECTA), denuncia esta práctica fraudulenta en el Diario Levante de 26 de enero de 2008, lo que demuestra la preocupación del asociacionismo cooperativo por el uso indebido de las cooperativas para privar de derechos laborales a los trabajadores. 
gentina ${ }^{11}$ llega a afirmar que "las cooperativas de trabajo constituyen una figura jurídica que ha generado grandes controversias debido a su uso fraudulento para encubrir relaciones laborales... Es posible encontrar cooperativas de trabajo para servicios de limpieza, recolección de fruta, transporte automotor, seguridad, etc. Pero este tipo de cooperativas también se diferencia del resto por haber generado fuertes controversias, debido a que en muchos casos se las utiliza para encubrir relaciones laborales tradicionales, especialmente en el caso de los trabajadores menos cualificados».

Desde la normativa, los hitos más importantes en la regulación de esta materia han sido los siguientes. En primer lugar, el Decreto 2015/1994, dispuso en su artículo 1 que «el Instituto Nacional de Acción Cooperativa (INAC) no autorizará el funcionamiento de cooperativas de trabajo que, para el cumplimiento de su objetivo social, prevean la contratación de los servicios cooperativos por terceras personas, utilizando la fuerza de trabajo de sus asociados». En desarrollo de este Decreto, una resolución del referido Instituto (Resolución INAC 1510/94) aclara que tal prohibición se extiende a las cooperativas que tengan como finalidad las actividades de agencia de colocación, limpieza, seguridad, distribuciones de correspondencia y servicios eventuales. Asimismo, incluye las que tengan como finalidad «la venta de fuerza de trabajo o mano de obra a terceros para dedicarlas a las tareas propias o específicas del objeto social de los establecimientos de estos últimos, de tal manera que dicha fuerza de trabajo o mano de obra constituya un medio esencial en su producción económica».

Finalmente, en 2004, la Ley 25.877, en su artículo 40, completa el concepto al declarar que las cooperativas de trabajo «no podrán actuar como empresas de provisión de servicios eventuales, ni de temporada, ni de cualquier otro modo, brindar servicios propios de agencias de colocación».

En el caso de otro estado iberoamericano, Brasil, tenemos un concienzudo análisis sobre el uso fraudulento de las cooperativas de trabajo, publicado recientemente por Nelson ${ }^{12}$, lo que demuestra la existencia de estas prácticas en ese país y la preocupación por este tema entre los estudiosos del cooperativismo. En este artículo, se denuncia la creación de cooperativas de trabajo con el fin de desnaturalizar una verdadera relación laboral, cuando el empleador simula esta relación a

11 Serie Informes de la Economía Real, Empleo y Desarrollo Social. N. 29 . Febrero 2011.

12 NELSON, R. A. R. R. «Do uso fraudulento das cooperativas de trabalho no Brasil». Deusto Estudios Cooperativos, n. ${ }^{\circ} 5$ (2014), Bilbao, pp. 135-153. 
través de un contrato de servicios con la cooperativa, que se convierte en un intermediario de mano de obra, en contra de todos los supuestos axiológicos de cooperación.

5. Creación de cooperativas instrumentales para facturar trabajos de autónomos

Si introducimos en un buscador de Internet una consulta del tipo ¿Cómo facturar sin pagar autónomos? o ¿Cómo facturar si cobro el paro? o ¿Cómo facturar trabajos esporádicos? Encontraremos numerosas respuestas que nos informan de la conveniencia de hacerse socio de alguna cooperativa que ofrece tal servicio y nos remitirán a ellas.

Estas cooperativas ofrecen los siguientes servicios:

- Asesoramiento legal y económico.

- Gestión de facturas.

- Alta en el Régimen General de la Seguridad Social sólo por los días trabajados.

- Contactos con empresas que puedan necesitar los servicios que prestan los socios.

Si analizamos los estatutos de estas cooperativas y los contratos que ofrecen a sus posibles socios, observaremos que se refieren a la realización de servicios profesionales dirigidos a personas que desarrollan una actividad de carácter eventual; y, a veces, estableciendo un límite máximo de facturación para poder ser socio. No hablan en su objeto social de "proporcionar puestos de trabajo a sus socios», elemento con el que definen el objeto de las cooperativas de trabajo todas las leyes de cooperativas ${ }^{13}$.

La cooperativa se ocupa de la gestión administrativa de la actividad ejercida por el socio y de orientar y facilitar la integración de éstos en el mundo laboral. Como podemos ver, lo que se ofrece nada tiene que ver con la participación en una cooperativa de trabajo; ya que los medios de producción están en manos de cada de uno de los socios y la actividad profesional no se realiza cooperativizadamente, ya que cada

13 Citaremos solamente la ley 27/1999, de 16 de julio, de Cooperativas, que define el objeto de estas cooperativas estableciendo que "Son cooperativas de trabajo asociado las que tienen por objeto proporcionar a sus socios puestos de trabajo, mediante su esfuerzo personal y directo, a tiempo parcial o completo, a través de la organización en común de la producción de bienes o servicios para terceros» (artículo 80.1). 
trabajo se realiza individuamente por un socio. Se ofrecen unas actuaciones propias de una cooperativa de servicios a profesionales. Y los socios de estos proyectos realmente son profesionales que buscan sus clientes a los que ofrecen sus servicios y, en su caso, se los prestan con sus propios medios productivos; pero, no asumiendo tal papel por tener unos ingresos considerados insuficientes para afrontar las cuotas del Régimen Especial de la Seguridad Social para los Trabajadores Autónomos y otros gastos que el establecimiento como profesional pudiera conllevar.

La cooperativa tramita el alta al socio en el Régimen General de la Seguridad Social por los periodos de actividad y procede a facturar al cliente los trabajos realizados, por lo que cobra las correspondientes comisiones. Estamos, pues, ante empresas que se dedican, realmente, a la actividad de gestoría y asesoría, que venden a sus clientes unos servicios, dándoles la naturaleza de socios de una hipotética cooperativa de trabajo, que no realiza ninguna actividad cooperativizada.

\section{Las nuevas fórmulas cooperativas previstas en la normativa aprobada recientemente: cooperativas de impulso empresarial}

Hasta ahora, hemos contemplado situaciones en las que un uso, no siempre correcto de la legislación cooperativa, conduce a la existencia de situaciones que no consideramos muy acordes con el respeto a lo que debe de ser la sociedad cooperativa y los principios que son propios de estas entidades en cuanto tales. Pero, ahora, vamos a dar un paso más. Se trata de analizar la existencia de regulaciones legales que nos hacen dudar de la verdadera naturaleza cooperativa de determinados tipos sociales previstos en las normas aprobadas más recientemente. Nos referimos a la regulación que de las denominadas cooperativas de impulso empresarial hacen las legislaciones autonómicas de cooperativas de Andalucía y Cantabria; y, que pretenden dar cobertura legal a las cooperativas que, anteriormente, calificábamos como instrumentales para facturar trabajos de autónomos.

\section{Ley 14/2011, de 23 de diciembre, de Sociedades Cooperativas Andaluzas}

Dentro de la clase de cooperativas de trabajo se contemplan a las sociedades cooperativas que la ley denomina de impulso empresarial y las regula en el artículo 93. La finalidad de éstas es canalizar las inquie- 
tudes emprendedoras de sus socios. Para ello, la ley fija cuáles serían los instrumentos básicos a su disposición, señalando los siguientes:

- Orientación profesional.

- Provisión de habilidades empresariales precisas para el desarrollo de cada una de sus actividades.

- Tutorización de dichas actividades en los primeros años de su ejercicio.

- Prestación de determinados servicios comunes a los socios para ofrecer un ámbito donde desempeñar regularmente su actividad profesional.

La lectura de las notas definitorias de estas sociedades nos lleva a pensar que el objeto de estas cooperativas es ofrecer acompañamiento a los emprendedores en los inicios de su actividad empresarial y dotarlos de una protección que les dote de cierta seguridad en esa primera etapa de puesta en marcha y lanzamiento de la misma. El objetivo último de la cooperativa debería ser que pasada esa etapa inicial, el profesional comenzase a realizar una auténtica actividad empresarial.

La propia exposición de motivos de la ley las atribuye el objetivo de contribuir desde el modelo cooperativo al afloramiento con carácter regular y colectivo de servicios que eventualmente se prestarían en el ámbito de la economía informal.

En la norma, se contempla la existencia de dos tipos de socios, los que prestan orientación, formación, tutoría o servicios complementarios, es decir, el personal de estructura de la sociedad cooperativa y los beneficiarios de dichas prestaciones, que habrán de ser personas físicas.

El artículo 93.3, remite al desarrollo reglamentario para la regulación de determinados aspectos de esta modalidad cooperativa, citando expresamente lo relativo a su objeto, duración de la prestación de trabajo, estatuto de los socios y ejercicio de derechos y deberes sociales.

2. Decreto 123/2014, de 2 de septiembre, por el que se aprueba el Reglamento de la Ley 14/2011, de 23 de diciembre, de Sociedades Cooperativas Andaluzas

El desarrollo reglamentario de esta figura societaria se ha llevado a cabo por el Decreto 123/2014, de 2 de septiembre, por el que se 
aprueba el Reglamento de la Ley 14/2011, de 23 de diciembre, de Sociedades Cooperativas Andaluzas, que dedica la Subsección 2.a , de la Sección 1. ${ }^{a}$, del Capítulo I, del Título II (artículos 81 a 86) a las cooperativas de impulso empresarial.

En el artículo 81.2, se declara que, con el fin de canalizar la iniciativa emprendedora de las personas socias, la actividad de estas cooperativas consistirá, o bien, en la orientación, formación, tutoría o prestación de servicios a sus socios y socias, o bien, en la realización de tareas de intermediación entre éstos y las terceras personas a las que prestan sus servicios. Como podemos ver en el reglamento se habla expresamente de actividad de intermediación, como objeto de estas cooperativas, que no se incluía en la ley.

Se prevé que sean los estatutos sociales de estas cooperativas los que especifiquen en el apartado relativo a su objeto social el desarrollo de una actividad $u$ otra, o la realización de ambas.

Pero la gran sorpresa que ofrece este reglamento, es que permite que esta figura tenga carácter estable, al señalar «La orientación, formación, tutoría o prestación de servicios que la cooperativa proporciona a sus personas socias podrá adoptar un carácter temporal, relacionadas con el lanzamiento de determinados proyectos empresariales, o un carácter estable, unidas al acompañamiento duradero de la actividad emprendedora; pudiendo asimismo la entidad armonizar ambas modalidades».

Por otro lado, el Reglamento permite que los estatutos sociales puedan prever la existencia de un porcentaje máximo de socios usuarios que puedan tener una vinculación de carácter intermitente, cuando desarrollen la actividad cooperativizada de manera esporádica. Esta posibilidad, se ve reforzada con la previsión que realiza el artículo 83, que permite, en primera instancia, que los estatutos fijen como causa específica de exclusión de los socios usuarios, que estos no alcancen durante tres meses consecutivos, o durante cinco meses en cómputo anual, un volumen de facturación igual o superior al salario mínimo interprofesional, correspondiente a dichos períodos. Pero, posteriormente, otorga la posibilidad de que los estatutos de la entidad puedan disponer que quienes no alcancen tales niveles de facturación sean considerados como socios usuarios de carácter intermitente.

Entendemos que estos dos aspectos son contrarios al verdadero espíritu de estas cooperativas, cuya misión es realizar una labor de acompañamiento a sus socios en el periodo inicial de su actividad profesional, pero que nunca debería ser permanente. La participación en este tipo de cooperativas como socio usuario tendría que estar limitada a 
un tiempo de duración máximo. Esta fase debe acabar con el establecimiento del socio usuario como autónomo o como miembro de un proyecto empresarial participativo nuevo y diferenciado de la cooperativa de impulso empresarial. La participación en la cooperativa nunca debería tener carácter finalista.

En el artículo 82, se utiliza la terminología de socios de estructura y socios usuarios. Los primeros prestarían orientación, formación, tutoría o servicios complementarios. Los segundos serían los beneficiarios de dichas prestaciones. El término de socios de estructura recuerda a la denominación utilizada normalmente para referirse al personal de las empresas de trabajo temporal, contratados por éstas para su gestión, no para cederlos a las empresas usuarias, a las que peligrosamente se pueden parecer estas cooperativas.

El Decreto obliga a estas sociedades cooperativas a regular en su reglamento de régimen interior, de acuerdo con lo previsto en el artículo 82.3, al menos, los siguientes extremos:

a) Supuestos en que se podrá compatibilizar la condición de persona socia de estructura y persona socia usuaria.

b) Fijación, en su caso, de un estatuto económico diferenciado para ambas clases de personas socias.

c) Trabajos que las personas socias de estructura deben prestar a los socios y socias usuarios, identificando, como mínimo, cuáles son, en que consisten, las condiciones técnicas de su prestación y su grado de permanencia.

d) Determinación del periodo de duración del acompañamiento a la actividad emprendedora.

e) Características específicas que deberán establecerse en los convenios de acompañamiento que, en su caso, suscriba la sociedad cooperativa con cada persona socia usuaria.

Como puede verse, algunos aspectos de esa regulación tienen gran importancia para la vida de la cooperativa, como son la posibilidad de compatibilizar la condición de socio de estructura y socio usuario, el diferente régimen económico de cada clase de socio o la duración de la actividad de acompañamiento al emprendedor, de los que creemos que la legislación debería haber regulado en mayor extensión y establecido unas normas mínimas de obligado cumplimiento al respecto.

En este Decreto, se regulan otros aspectos, como determinados supuestos relativos al derecho de voto, la garantía financiera a prestar por este tipo de entidades, el sometimiento a auditoría de cuentas o la elaboración y publicidad de su carta de servicios, aspectos que no son relevantes para los objetivos de este análisis. 
3. Ley de Cantabria 6/2013, de 6 de noviembre, de Cooperativas de Cantabria

Esta ley claramente inspirada en este aspecto en la Ley de Sociedades Cooperativas Andaluzas, regula las cooperativas de impulso empresarial y ya en el preámbulo de la ley se dice que pretenden facilitar la innovación social desde un estricto cumplimiento de los principios cooperativos. Esta referencia al respeto de los principios que no aparece en ninguna otra clase de cooperativa, parece denotar ya una cierta desconfianza del legislador hacia esta figura. Se continúa diciendo que se trata de una eficaz herramienta de fomento del emprendimiento de sus socios, capaz de conseguir el afloramiento de servicios que de otro modo permanecerían en el ámbito de la economía informal.

Dedica la ley a estas cooperativas, el artículo 130, dentro del capítulo destinado a regular las cooperativas especiales. No se sigue el modelo andaluz de conceptualizarla como un subtipo de las cooperativas de trabajo.

Define estas sociedades cooperativas de impulso empresarial como aquellas que tienen como objeto canalizar la iniciativa emprendedora de sus socios, mediante la orientación profesional, la provisión de habilidades empresariales, o la prestación de servicios comunes. También podrán tener por objeto la intermediación laboral, a través de la normalización y regularización de actividades económicas informales. Esta redacción supone, respecto a la ley andaluza, dos importantes novedades, que la hacen aún más atrevida. Por un lado, incluye en la definición de estas cooperativas el reconocimiento de las mismas como alternativa a la economía sumergida (la ley andaluza sólo lo indica en su Preámbulo) y se le reconoce la capacidad de ejercer la intermediación laboral, que se recoge en el reglamento de desarrollo de la ley andaluza.

Prevé, también, que puedan existir dos tipos de socios:

- Los socios prestadores de servicios o de estructura, que podrán ser personas físicas o jurídicas, públicas o privadas. Son los responsables del correcto funcionamiento social, económico y financiero de la cooperativa.

- Los socios ordinarios o receptores de servicios, que podrán ser únicamente personas físicas, y prestarán su trabajo a través de la cooperativa.

Al igual que hace la Ley de Sociedades Cooperativas Andaluzas, se remite al desarrollo reglamentario para la regulación de determinados aspectos de esta modalidad de cooperativa, especialmente lo relativo 
a su objeto, duración de la prestación de trabajo, estatuto del socio y ejercicio de derechos y deberes. Hay que tener en cuenta que la Ley de Cooperativas de Cantabria no prevé la existencia de normas reglamentarias que desarrollen ésta en su totalidad ${ }^{14}$ (a diferencia de la ley andaluza); y, en cambio, sí deja el desarrollo de esta figura a esa fase reglamentaria. Parece que, por tanto, para la efectiva posibilidad de creación de estas cooperativas, hay que esperar a su desarrollo reglamentario, siendo el único caso en el que se efectúa tal previsión, lo que demuestra las dudas que ofrece esta figura al propio legislador, que parece pensar que se actuará, en un futuro, desde el poder ejecutivo, en función de cómo resulte la experiencia en otras Comunidades Autónomas, especialmente, en Andalucía, de donde emana directamente la regulación que se hace en esta ley.

\section{Reflexiones sobre estas cooperativas}

La regulación de estas cooperativas es una demostración del uso no siempre afortunado que se está haciendo por parte de los poderes autonómicos de la potestad legislativa en materia de sociedades cooperativas. Las Comunidades Autónomas no tienen competencia para legislar otras formas empresariales, por lo que se utiliza la normativa de cooperativas para dar visos de legalidad a todas aquellas situaciones que no tienen cabida en la legislación empresarial del Estado. Se corre el riesgo de hacer de la legislación de cooperativas un «cajón de sastre» que otorgue cobertura a todas aquellas modalidades empresariales que no tienen cabida bajo otras formas jurídicas.

Esta cooperativa está pensada, como insistíamos anteriormente, para que los emprendedores actúen bajo el amparo de ésta durante un tiempo, antes de dar el paso a ser autónomo o constituir una nueva empresa de carácter asociativo y no incurrir en los gastos que esta constitución conlleva, hasta no constatar la viabilidad de su proyecto. El socio realiza el trabajo, que es facturado a través de la cooperativa que tramita su alta en Seguridad Social por los periodos efectivos de actividad. Pero, como apuntábamos antes, la realidad puede hacer que se

14 La Ley 6/2013, de Cooperativas de Cantabria, sólo remite a desarrollo reglamentario, además de este tipo de cooperativas, el régimen jurídico del Registro de Sociedades Cooperativas de la Comunidad Autónoma de Cantabria (art. 136.2), determinados aspectos de la organización y funcionamiento del Consejo Cántabro de la Economía Social (art. 143.3) y habilita para la regulación reglamentaria de nuevos subtipos de cooperativas (art. 99,4). 
conviertan en empresas de trabajo temporal o agencias privadas de colocación sin autorización administrativa para actuar como tales, ya que, en ocasiones, los clientes se dirigirán directamente a la cooperativa, de quien tendría referencia por las facturas emitidas por trabajos anteriores, para que se les preste determinado servicio y será ésta quien decida a que socio o socios se les otorga el trabajo. También, puede convertirse en un mecanismo para camuflar trabajadores autónomos, que puedan acceder, por esta vía, indebidamente, al Régimen General de la Seguridad Social.

Podemos pensar que se trata de un exceso de celo de los poderes legislativos en el cumplimiento del mandato constitucional de fomentar el cooperativismo. Se pretende dar el nombre de cooperativa a realidades que son dudosas de merecer tal denominación y parece que lo único relevante es el número de sociedades constituidas. No debemos olvidar que la Constitución Española15 cita expresamente una única persona jurídica con actividad económica, y ésta es la sociedad cooperativa; por lo tanto, hay que exigir a los poderes públicos tanto una política efectiva de fomento del cooperativismo, como el rigor en las normas que regulan las cooperativas y no dar tal calificación a empresas que no son tales, porque en una cooperativa de trabajo los medios de producción son de titularidad de ésta y aquí no hay medio de producción alguno que no sea de titularidad del respectivo socio, que, en ningún caso, cooperativiza su trabajo.

Estos riesgos parecen ser entendidos por el legislador de Cantabria que remite a un desarrollo reglamentario de determinados aspectos, como hemos dicho antes, entre los que se encuentra el principal, a nuestro juicio, cuánto tiempo puede el socio prestar servicios en la cooperativa, ya que su objeto último es dar al emprendedor un periodo de rodaje, para que, posteriormente, proceda a su propio establecimiento como empresario. La propia referencia, ya citada, al difícil equilibrio que hay entre esta innovación social y el respeto a los principios cooperativos, específicamente en este tipo de cooperativas, muestra las sombras que aún se ciernen sobre esta figura, que, como decíamos anteriormente, da la impresión de que se está esperando a ver cómo se plasman en la realidad en otras regiones para ofrecer esta alternativa realmente, a partir de su desarrollo reglamentario, que esperamos re-

15 SANZ DOMíNGUEZ, C. "Consideraciones en torno al fomento de las sociedades cooperativas en el ordenamiento jurídico español».

Disponible en http://www.uhu.es/publicaciones/ojs/index.php/trabajo/article/ view/193 
coja, en su caso, la vinculación siempre temporal del socio usuario con la sociedad cooperativa.

\section{Medidas de vigilancia y actividades de inspección}

Las funciones inspectoras en materia de sociedades cooperativas, en cuanto tales están otorgadas con carácter general a la Inspección de Trabajo y Seguridad Social (ITSS) ${ }^{16}$. El control del cumplimiento de las normas laborales, de fomento de empleo y de Seguridad Social a las que nos hemos referido en este estudio, también, son competencia de dicho órgano. Pero, hay otras materias, como las fiscales, que dependerán del control de las agencias tributarias, tanto estatal como autonómicas. A esto, habría que sumar el control que, en su caso, llevarán a cabo las autoridades de consumo, industria, medio ambiente, ordenación de los transportes, comercio,... sobre todo, cuando son gestoras de subvenciones públicas que tengan como destinatarias a empresas con forma de sociedad cooperativa.

Ante este panorama, de multiplicidad de administraciones y órganos que tienen responsabilidades en la vigilancia de estas sociedades es muy importante que por parte de todos los que asumen competencias en la materia se planifiquen y ejecuten programas de vigilancia y control del correcto uso de la figura de la sociedad cooperativa, ya que con la realización de actuaciones como las que hemos denunciado anteriormente, se perjudica a toda la sociedad. Creemos que se puede hacer más para tratar de minimizar los efectos de las prácticas indebidas que hemos analizado.

Cuando intervienen tantos órganos como ocurre en este caso (Registro de Cooperativas, órganos gestores de ayudas públicas, administraciones tributarias y de Seguridad Social, órganos encargados de la labor inspectora,...) resulta muy difícil establecer cauces óptimos de comprobación del grado de cumplimiento de la normativa; pero, nos atrevemos a apuntar una serie de medidas que pueden mejorar ese aspecto:

1. Establecer en la normativa, lo más claramente posible, los supuestos fraudulentos y las consecuencias sancionadoras de los mismos.

16 Únicamente las leyes de cooperativas de País Vasco, Comunidad Valenciana, Castilla-La Mancha y Andalucía no atribuyen expresamente esta competencia a la Inspección de Trabajo y Seguridad Social. 
En las leyes de cooperativas, se contemplan expresamente infracciones que ponen el acento en actuaciones que vulneran la esencia misma de la cooperativa; pero, sería necesario un mayor esfuerzo en la tipificación de conductas para dificultar determinadas prácticas abusivas. Así, podemos constatar la tipificación de las siguientes infracciones:

a) La paralización de la actividad cooperativizada durante dos años. Es recogida en prácticamente todas las leyes de cooperativas. Este tipo serviría para actuar frente a las falsas cooperativas en las que no existe una actividad real de la asamblea general.

b) Incumplir las normas legales y estatutarias relativas al objeto y finalidad de la cooperativa (Se recoge en las leyes de cooperativas de Islas Baleares, Cataluña, Euskadi, La Rioja, Galicia y Andalucía). Esta fórmula abierta puede resultar un poco imprecisa para incluir algunos supuestos.

c) Encubrir, bajo la fórmula de sociedad cooperativa, finalidades propias de sociedades mercantiles (Se recoge en las leyes de Cataluña e Islas Baleares).

d) Desvirtuación de la cooperativa, cuando se violen de forma reiterada los principios cooperativos o cuando se admitan como socios a personas que legalmente no pueden serlo (Ley de Cooperativas de la Comunidad Valenciana).

En el Real Decreto Legislativo 5/2000, de 4 de agosto, por el que se aprueba el texto refundido de la Ley de Infracciones y Sanciones en el Orden Social (LISOS) se tipifican diferentes infracciones en materia laboral, de empleo y de Seguridad Social en los que se pueden incluir algunos de los supuestos antes referidos; pero, sería necesaria una mayor precisión en la tipificación de conductas ya detectadas en la actuación inspectora para evitar que resulte difícil encuadrarlas en los tipos previstos en la ley.

2. Coordinación entre las administraciones y órganos con competencias en materia de sociedades cooperativas.

3. Impulsar los Registros de Cooperativas y dotarlos adecuadamente para que canalicen, en cierta medida, la coordinación de esas actividades de control con las agencias tributarias. tanto estatal como autonómicas, los órganos de Seguridad Social, Servicios Públicos de Empleo, órganos encargados de la gestión y concesión de ayudas públicas, Inspección de Trabajo y Seguridad Social, al ser estos registros los que disponen de gran parte de 
la información que puede resultar relevante para actuaciones de otros órganos.

4. Incluir en los programas anuales de objetivos de la ITSS (o, en su caso, del órgano que tenga encomendada la función de inspección en materia de sociedades cooperativas) actuaciones de control del cumplimiento de la legislación cooperativa. Asimismo, realizar campañas específicas de control del cumplimiento de la legislación en materia laboral y de Seguridad Social en empresas cooperativas.

5. Fomentar el compromiso de los diferentes consejos de cooperativismo o de economía social para impulsar la lucha contra el fraude. En ellos tienen representación las administraciones y las entidades asociativas de estas empresas y ambos agentes son los más interesados en que afloren estas situaciones, para erradicarlas. Estos consejos pueden ser los foros adecuados para planificar las líneas básicas de actuación en la materia.

6. Al margen de estos consejos, debe de lograrse la implicación de las entidades asociativas de cooperativas en este proceso. Las prácticas denunciadas, y la publicidad que de las mismas se realiza, en ocasiones, suponen un grave descrédito para el sector en su conjunto, por lo que estas organizaciones deben prestar su colaboración para contribuir a terminar con estas situaciones de fraude que ensucian el buen nombre del cooperativismo.

\section{Bibliografía}

Fernández OrRico, F. J. «La Inspección de Trabajo frente al fraude en las prestaciones de Seguridad Social». Ministerio de Empleo y Seguridad Social. 2014.

Martínez GarRIDO, L. R., "Contratas, cesión ilegal de trabajadores y cooperativas de trabajo asociado». Revistas del Ministerio de Trabajo y Asuntos Sociales, n. ${ }^{\circ}$ 38. 2002. Pp. 229-239.

Nelson, R. A. R. R. «Do uso fraudulento das cooperativas de trabalho no Brasil». Deusto Estudios Cooperativos, n. ${ }^{\circ} 5$ (2014), Bilbao, pp. 135-153.

Sanz Domínguez, C. "Consideraciones en torno al fomento de las sociedades cooperativas en el ordenamiento jurídico español». Disponible en http:// www.uhu.es/publicaciones/ojs/index.php/trabajo/article/view/193

ZUBIRI DE SALINAS, M. «Las empresas gestoras de cooperativas de viviendas tras la reforma de la Ley de Cooperativas de Aragón. Revista: Actas del Foro de Derecho Aragonés Volumen: XX; pp. 261-276. 